\title{
A SEPARAÇÃO DOS PODERES (FUNÇÕES) NOS DIAS ATUAIS
}

\author{
AMÉRICO BEDÊ FREIRE JÚNIOR*
}

$O$ direito atualmente se encontra 'hamletianamente' martirizado pelo dilema de ser arte ou ciência. Ou seja, entre ser 'tecnologia de controle', organização e direção social, o que implica uma formação unidisciplinar, meramente informativa, despolitizada e adestradora, estruturada em torno de um sistema jurídico tido como auto-suficiente, completo, lógico e formalmente coerente; ou ser uma 'atividade verdadeiramente cientifica, de natureza problematizante, eminentemente especulativa e acima de tudo crítica - o que exige uma formação reflexiva, não-dogmática e multidisciplinar, organizada a partir de uma interrogação sobre a dimensão politica, sobre as implicações sócio-econômicas e sobre a natureza ideológica de toda ordem jurídica. (José Eduardo Faria)

O Princípio da Separação dos Poderes'. cláusula pétrea da Constituição brasileira, encontra-se positivado no artigo $2^{\circ}$ ao prever que são Poderes da União, independentes e harmônicos entre si, o Legislativo, o Executivo e o Judiciário.

Nos estreitos limites desse trabalho não cabe tecer a evolução histórica do princípio ${ }^{2}$ em comento, mas sim desvendar o alcance em nosso tempo do princípio.

De início, e essa afirmação terá importantíssimas consequêencias ao longo do texto, é de se frisar que em verdade a nomenclatura separação de poderes não deve prosperar, uma vez que, efetivamente, o poder estatal é uno.

* Juiz Federal Substituto em Vitória/ES, Mostrando em Direitos Fundamentais/FDV, Professor da FDV, ex-Promotor de Justiça/MA.

1 Esse capítulo não se deterá em todas as facetas do princípio da separação dos poderes. Efetivamente, Flávia Viveiros, por exemplo, aponta oito sentidos distintos em que pode ser utilizada a expressão separação dos poderes ver DE CASTRO, Flávia Viveiros. O Princípio da Separação dos Poderes in Os Principios Constitucionais de 1988. Rio de Janeiro: Lúmen Júris, 2001.

2 Cabe destacar que a posição majoritária na doutrina é encontrar em Montesquieu o grande divulgador do princípio, todavia faz-se mister destacar que Locke deve ser considerado, no mínimo, o precursor da separação dos poderes. 
Há, portanto, em nosso país uma separação de funções ${ }^{3}$ e não de Poderes, até porque na verdade todos os "poderes" estão abaixo da Constituição.

Essa correção terminológica funcionará como premissa hermenêutica no presente trabalho, deveras o Poder Estatal é um só, materializado na Constituição, de onde extrai-se que a separação das funções deve funcionar também como forma de viabilizar a máxima efetividade das normas constitucionais.

Após essa breve contextualização, devemos minudenciar o núcleo essencial do princípio da separação de funções no Estado Democrático de Direito, que não pode funcionar apenas com a concepção liberal de proteção da burguesia em face da concentração de poder Estatal.

Paulo Suordem ${ }^{4}$ sustenta como núcleo do princípio: "na sua dimensão orgânico-funcional, o princípio da separação dos poderes deve continuar a ser encarado como princípio da moderação, racionalização e limitação do poder político estatal, no interesse da liberdade. Tal constitui seguramente o seu núcleo imutável".

Verifica-se dessa definição que a separação dos poderes não é um fim em si mesmo, mas um instrumento concebido com o intuito de viabilizar uma efetividade às conquistas obtidas com o movimento constitucionalista.

Sem dúvida alguma a principal característica do movimento constitucionalista foi a afirmação dos direitos fundamentais como epicentro do Sistema jurídico.

Nesse diapasão deve ser frisado que não apenas os direitos da primeira dimensão devem ser protegidos pela separação dos poderes, mas todas as dimensões dos direitos fundamentais, já que uma das características dos direitos fundamentais é a sua indivisibilidade, portanto todas as dimensões dos direitos fundamentais podem (devem) ser protegida pelo princípio em comento.

Ora, constata-se, portanto, ser um arrematado absurdo apontar o princípio da separação dos poderes como entrave a efetivação de direitos fundamentais, uma vez que tal interpretação aniquila a efetividade (correta aplicação) da separação dos poderes.

Se a Declaração de direitos do Homem e do cidadão ${ }^{5}$ pontificava em seu artigo 16 que "Toute société dons laquelle la gaarantie des droits n'est pás assurée, ni la separation des pouvoirs déterminée, $n^{\prime}$ a point de constitution ${ }^{6}$; devemos reconhecer a profunda ligação entre os direitos fundamentais e a separação dos poderes, sendo essa última expressão meio para atingirmos o desiderato maior de proteção dos direitos fundamentais.

3 Há autores que falam em hexapartição de poderes, ver SOUZA Júnior, Cezar Saldanha. $O$ Tribunal Constitucional como Poder. Por uma nova Teoria da Divisão dos Poderes. São Paulo: Memória Jurídica, 2002.

4 SUORDEM, Fernando. O Princípio da Separaçāo dos Poderes e os Novos movimentos sociaisA Administração Pública no Estado Moderno: Entre as exigências de liberdade e Organização, Coimbra: Almedina, 1995.

5 A título de curiosidade, frise-se que foi discutida à época a elaboração de uma declaração de direitos da cidadã.

6 Em tradução livre "Toda sociedade na qual a garantia dos direitos não for assegurada, nem a repartição dos poderes determinada, não tem constituição." 
Verifica-se então que já está passando a hora da releitura da separação dos poderes, como forma de efetivação da Constituição no Estado Democrático de Direito.

Tal releitura busca especialmente redimensionar a função judicial na materialização da Constituição, pois efetivamente a Carta Magna escrita não pode ser a mera folha de papel tão acidamente criticada por Lassale.

Observa-se, então, que a função que imperiosamente deve ser revista é a função judicial, posto que na concepção tradicional de separação dos poderes o Poder Judiciário somente tinha plenitude nas relações privadas, sendo que o espaço público deveria ser ocupado apenas pelos eleitos pela população.

Inicialmente, cabe, nessa proposta de revisão do papel do judiciário, trazer à baila três lúcidas ponderações de eminentes autores do direito a saber:

Lenio Streck ${ }^{7}$ aponta que a partir da nova ordem jurídica inaugurada pela Carta da República de 1988 as "inércias do executivo e falta de atuação do legislativo passam a poder ser supridas pelo judiciário, justamente mediante a utilização dos mecanismos previstos na Constituição que estabeleceu o Estado Democrático de Direito. Ou isto, ou tais mecanismos legais/constitucionais podem ser expungidos do texto magno".

$\mathrm{Krell}^{8}$ afirma peremptoriamente que "Parece-nos cada vez mais necessária à revisão do vetusto dogma da Separação dos poderes em relação ao controle dos gastos públicos e da prestação dos serviços sociais básicos no Estado Social, visto que os Poderes Legislativos e Executivo no Brasil se mostram incapazes de garantir um cumprimento racional dos respectivos preceitos constitucionais".

Cappelletti ${ }^{9}$, por fim, já lecionava a necessidade de um judiciário distinto do tradicional, afirmando o mestre de Florença com precisão:

"Mas a dura realidade da história moderna logo demonstrou que os Tribunais - tanto que confrontados pelas duas formas acima mencionadas de gigantismo estatal, o legislativo e o administrativo - não podem fugir de uma inflexível alternativa. Eles devem de fato escolher uma das duas possibilidades seguintes: a) permanecer fiéis, com pertinácia, à concepção tradicional, tipicamente do século $X I X$, dos limites da função jurisdicional, ou b) elevar-se ao nivel dos outros poderes, tornar-se enfim o terceiro gigante, capaz de controlar o legislador mastodonte e o leviatanesco administrador."

Pode-se tranqüilamente extrair-se das passagens retrocitadas uma preocupação comum, qual seja, a de que haja um novo perfil da atuação do Poder Judiciário, permitindo a efetivação dos direitos fundamentais.

7 STRECK, Lênio Luiz. In 1988-1998, uma década de Constituição; As constituições sociais e a dignidade da pessoa humana como principio fundamental, p. 323.

8 KRELL, Andréas. Controle Judicial dos serviços públicos básicos na base dos direitos fundamentais sociais. A Constituição Concretizada Construindo pontes com o público e o privado. Porto Alegre: Livraria do Advogado 2000, p. 29.

9 CAPPELLETTI, Mauro. Juizes Legisladores? Porto Alegre: Sérgio Antônio Fabris, 1999, p. 
Frise-se que tal proposta não se enquadra como um mero juízo subjetivo, mas sim como uma realidade que vem a cada dia demonstrando a sua aceitação e importância na materialização da Constituição.

É certo que uma postura mais ativa do Judiciário implica em possíveis zonas de tensões com as demais funções do Poder, todavia não se defende uma supremacia de qualquer das funções, mas sim a supremacia da Constituição, que implica que o Judiciário não é um mero carimbador de decisões políticas das demais funções.

A eventual colisão de funções ${ }^{10}$ não é um argumento válido para refutar o aprimoramento da função judicial em prol da melhor aplicação possível da Constituição, posto que existem em todas as constituições critérios prévios para a definição de soluções na hipótese de choques entre as funções, como por exemplo o controle de constitucionalidade ${ }^{1 !}$.

Outro aspecto relevante que obriga a releitura da separação das funções é a adoção de um novo papel aos princípios constitucionais ${ }^{12}$.

Como pontificou com precisão Daniel Sarmento ${ }^{13}$ : "As Constituições são compostas por princípios e regras jurídicas. Uma Constituição que só contivesse princípios não emprestaria a segurança jurídica e previsibilidade necessárias ao ordenamento, ma suma Constituição fundada exclusivamente em regras não possuiria a plasticidade necessária à acomodação dos conflitos que eclodem na sociedade"

Ora, os princípios provocam irrefutavelmente uma postura distinta do juiz, uma vez que a densificação da norma constitucional pode (deve) ocorrer diretamente (imediatamente) através do juiz ${ }^{14}$.

A dignidade da pessoa humana passa a não ser apenas um mero discurso, ma suma norma que se possa extrair efetividade para impedir ações públicas ou particulares contrárias, mesmo que não exista uma lei explicitando o conteúdo do princípio.

O dogma da completude do sistema jurídica através do legislador está sepultado, hoje somente é possível falar na completude do sistema a partir de uma Constituição principiológica que requer um novo papel dos interpretes, especialmente dos juízes.

Ora, como pontificou Ney Barros Bello Filho ${ }^{15}: "$ A Constituição compõe-se de texto e de realidade. Há um binômio do qual não pode fugir o intérprete. $\mathrm{O}$ espaço

10 Independência e harmonia são palavras que quase sempre no mundo fático entram em rota de colisão.

11 Situação particularmente dramática é quando o órgão de controle declara determinada norma inconstitucional e o parlamento (função controlada) ato contínuo emenda à Constituição, retirando, por conseguinte, o fundamento para a declaração de inconstitucionalidade esvaziando o controle.

12 Nos estreitos limites desse trabalho não se irá explicar conceitualmente os critérios que permitem a distinção entre regras e princípios, distinção essa tomada como pressuposto, ver por todos ALEXY, Robert. Teoria de los derechos fundamentales. Tradução de Ernesto Garzón Valdes. Madrid: Centro de Estúdios Constitucionales, 1993.

13 SARMENTO, Daniel. A Ponderação de Interesses na Constituiçâo Federal. Rio de janeiro: Lúmen Júris, 2000, p 195.

14 Suplanta-se a posição de que necessariamente a efetivação da Constituição deveria primeiramente passar pelo legislador para, então, ter condições de ser reconhecida judicialmente. 
constitucional compõe-se de dois planos: o texto e a realidade. Isso implica em dizer que a concepção que isola o fenômeno constitucional em apenas um dos campos o texto ou a realidade - são visões redutoras de um espaço complexo".

É preciso, portanto, conciliar o texto constitucional com uma prática constitucional adequada, e tal missão somente pode ser cumprida se o Poder Judiciário não pensar mas no dogma do princípio liberal da legalidade, mas sim em um princípio maior o da Constitucionalidade dos atos.

O legislador não é o único responsável por viabilizar a Constituição; o juiz tem a missão constitucional de impedir ações ou omissões contrárias ao texto, sem que com essa atitude esteja violando a Constituição.

O juiz não é a mais a simples boca da lei, mas sim interprete constitucional qualificado ${ }^{16}$ que vai permitir que a Constituição não soçobre numa realidade instável como a que vivemos.

Tal postura é ínsita a nova leitura da separação de poderes, adequada a nosso tempo de globalização e falta de paradigmas. Não podemos pensar a separação de poderes com os fundamentos de uma sociedade que não mais existe ${ }^{17}$, ao contrário devemos construir um princípio que possa ter aplicação em nossos dias.

Para o cumprimento desse mister é indispensável vislumbrar no princípio da separação de funções não um fim em si mesmo, mas um meio para a efetivação da Constituição, devendo, portanto, nesse novo momento o judiciário atuar diretamente na preservação da supremacia da constituição.

Para concluir devemos lembrar preciosa afirmação da Associação de Professores alemães de Direito Político que ao destacar a importância do Tribunal Constitucional $^{18}$ (função exercida pelo Poder Judiciário no Brasil) que pontificaram:

"No es concebible uma Ley Fundamental en la que desapareciera el Tribunal Constitucional, com sus amplias competencias, sin que aquélla sufriera uma reforma em su esencia. El Tribunal Constitucional se há evidenciado como el más importante garante del respeto por el resto de los órganos estatales al Derecho Constitucional. La consiguiente contención de poder político em beneficio de la normatividad de la Constitución há hecho arraigar el importante significado de la ley Fundamental em la conciencia social y há contribuido considerablemente a la consolidación del nuevo orden político."

15 BELLO Filho, Ney Barros. Sistema Constitucional Aberto. Belo Horizonte: Del Rey, 2003, p. 23.

16 Não podemos olvidar que qualquer cidadão é um legítimo interprete da Constituição, só que somente os juizes o fazem com força coercitiva.

17 Como afirmou Calmon de Passos em recente palestra, "A sociedade do século passado estava em seu modo de viver e conviver muito mais próxima da antigüidade clássica de que de nosso tempo".

18 APUD SIMON, Heimut. La Jurisdicción Constitucional. Manual de Derecho Constitucional. Org. Benda, Maihofer, Vogel, Hesse e Heyde. Barcelona: Marcial Pons Ediciones Jurídicas y sociales. S.A 2001. 


\title{
Contrato com Pessoa a Declarar
}

\author{
Luiz Roldão de Freitas Gomes
}

Luiz Roldāo de Freitas Gomes

\section{CONTRATO} COM PESSOA

\section{A DECLARAR}

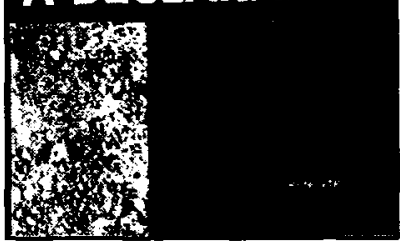

O autor sustenta que justifica-se a utilização da nova figura por uma série de razōes de ordem prática, tais como: a) evitar que o proprietário eleve o preço; b) possibilitar o condômino que recorra a outrem, para adquirir a cota do co-proprietário; c) evitar taxaçào quando o comprador adquire com a intenção de revender o imóvel a quem melhor preço lhe ofereça; d) possibilitar intermediação nos negócios; e) regularizar as aquisiçōes em leilões e hastas públicas; $f$ ) regularizar as vendas de automóveis a agências.

\begin{tabular}{|c|c|}
\hline 0073 & Brochura \\
\hline
\end{tabular}

\section{Contrato de Câmbio de Exportação em Juízo}

Fernando G. M. Cavalcanti

Obra indispensável para todos que militam na área de exportação, o autor, de forma didática, torna comum as complexas relações que envolvem o comércio exportador. No mais completo trabalho, analisando com segurança, método e de forma igualmente didática as conseqüências da inadimplência dos contratos de câmbio, preenchendo um vazio de que se ressentiam os interessados e facilitando sobremodo a vida dos profissionais da área.

Ref. 0017

Form. 14x21
Brochura 1989
242 págs.
Femando G.M.Cavalcanti

CONTRATO IRE CAMBO DE EXPOR'TACT̃O BM JUIZO

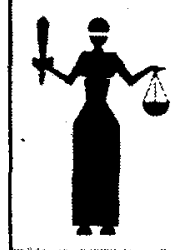

RENOVAR 